\title{
Shakespeare on alcohol
}

In this "Between the lines" piece by Theodore Dalrymple (BMJ 2011;342:d1789, doi:10.1136/bmj.d1789) we put a closing quote mark in the wrong place, thus inadvertently attributing the query "Who has never been cornered by a drunk who thinks that he is being witty?" to Falstaff in Henry IV Part II. The question was, in fact, asked by the author of the piece.

Cite this as: $B M J$ 2011;342:d2305 